\title{
Shear Behavior in Indented Concrete Layers with Different Strengths
}

\author{
Jae-Yoon Kang*, Jong-Sup Park, Woo-Tai Jung, Moon-Seoung Keum \\ Structural Engineering Research Institute, Korea Institute of Civil Engineering and Building Technology, Goyang, \\ Republic of Korea \\ Email: ‘jykang@kict.re.kr, jspark1@kict.re.kr, woody@kict.re.kr, moonseoung@kict.re.kr
}

Received 29 June 2016; accepted 16 July 2016; published 19 July 2016

Copyright $(\subset 2016$ by authors and Scientific Research Publishing Inc.

This work is licensed under the Creative Commons Attribution International License (CC BY).

http://creativecommons.org/licenses/by/4.0/

(c) (i) Open Access

\begin{abstract}
This paper investigates the design formula for the shear strength at the concrete-to-concrete interface proposed in Eurocode with regard to concrete layers with different strengths. Based upon the results of the study on the applicability of the design formula, push-off test is conducted on specimens with various indented interfaces to evaluate the actual behavior with respect to the surface roughness. The experimental results reveal that the interfacial shear strength increases with higher compressive strength of the concrete layers presenting different strengths and that the shear strength at the indented interface differs by $20 \%$ to $50 \%$ compared to the value predicted by the design formula. Especially, the shear strength developed between the concrete layers with different strengths appears to be different from the prediction of the design formula as much as the layers present larger difference in their compressive strengths.
\end{abstract}

\section{Keywords}

Shear Strength, Interface of Concrete Layers, Surface Roughness, Indented Surface, Push-Off Test

\section{Introduction}

The transfer mechanism of the shear stress developed in members made of concrete layers with different strengths is extremely complex since it is influenced by diverse factors including the reinforcement crossing the interface, the resistance to compression of concrete with low strength, the roughness level of the interface and the stresses generated by the loads normal to the interface. Research on this mechanism started in 1960s and was pursued by Hanson [1], Birkeland and Birkeland [2], Mattock and Hawkins [3], Walraven and Reinhardt [4], and Loov and Patrnaik [5] who conducted various studies on the shear friction behavior. Recently, the works of Júlio and Santos [6] [7] were recognized as providing the theory elucidating the transfer mechanism of the shear

${ }^{*}$ Corresponding author. 
stress developed at the interface of concrete layers, which is currently adopted in the design specifications of Eurocode [8]. These authors explained that the development of this shear resistance is the result of the combination of the adhesive bond caused by the separate placing of the layers, the dowel action of the reinforcement, and the friction generated after the occurrence of interfacial cracks [1].

The present study proposes the hybrid girder shown in Figure 1 aiming to reduce the depth of the conventional steel girder-concrete slab composite bridge by composing the upper flange of the steel girder with a casing made of 80-MPa ultra high performance concrete. For the composite bridge using the hybrid girder, the design formula for the shear strength suggested in Eurocode is applied to determine the amount of shear reinforcement necessary to compose the $80-\mathrm{MPa}$ concrete of the casing and the 30-MPa concrete of the slab. However, this formula does not reflect the difference in strength between the concrete layers and need is to examine its applicability. Therefore, Kang et al. [9] evaluated the shear strength in concrete layers with different strengths with respect to the interfacial condition between concrete layers by finite element analysis (FEA) and the results showed that the analytical result is larger by 1.3 - 1.4 times than the value calculated by the design formula. So, in this study, to understand the real behavior of shear in concrete layers, push-out test is conducted on specimens presenting various concrete strength, amount of shear reinforcement and interfacial condition to examine the difference between the prediction of the Eurocode's design formula and the actual behavior of the members made of concrete layers with different strengths.

\section{Evaluation of Design Formula for Interfacial Shear Strength with Indented Surface}

Eurocode proposes the formula in Equation (1) for the evaluation of the shear strength at the interface of concrete layers placed as different times. This formula is composed of three terms.

$$
v_{R d i}=c f_{c t d}+\mu \sigma_{n}+\rho f_{s y d}(\mu \sin \alpha+\cos \alpha) \leq 0.5 v f_{c d}
$$

The first term $c f_{c t d}$ is the adhesion resistance between the materials at the interface and is determined by the design tensile strength of concrete $\left(f_{c t d}\right)$. The second term $\mu \sigma_{n}$ is the shear frictional resistance generated by the normalstress $\left(\sigma_{n}\right)$ caused by the external forces and is determined by the surface roughness $(\mu)$. The third term $\rho f_{\text {syd }}(\mu \sin \alpha+\cos \alpha)$ is the shear resistance provided by the shear reinforcement and is determined by the steel ratio $(\rho)$, the yield strength of the rebar ( $\left.f_{\text {syd }}\right)$, the angle of inclination of the rebar $(\alpha)$ and the surface roughness $(\mu)$. The values of the coefficients $c$ and $\mu$ are given in Table 1 according to the roughness of the interface.

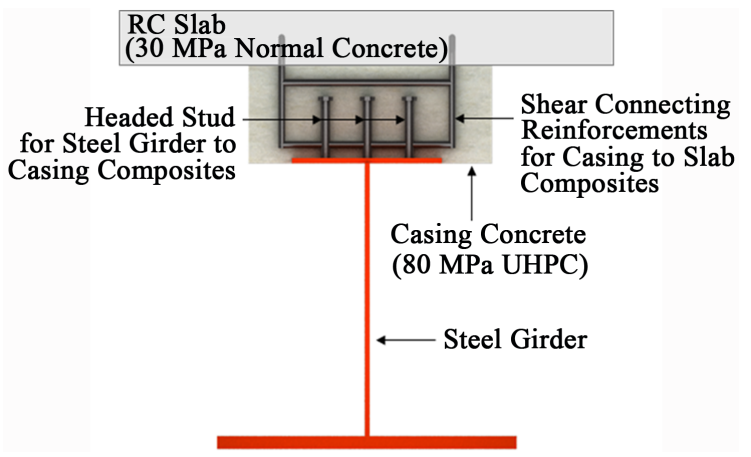

Figure 1. Concept of steel girder-UHPC casing hybrid girder.

Table 1. Factors which depend on the roughness of the interface [8].

\begin{tabular}{|c|c|c|c|}
\hline Surface condition & $c$ & $\mu$ & Remarks \\
\hline Very smooth & 0.25 & 0.5 & A surface cast against steel, plastic or specially prepared wooden moulds \\
\hline Smooth & 0.35 & 0.6 & A free surface left without further treatment after vibration \\
\hline Rough & 0.45 & 0.7 & $\begin{array}{l}\text { A surface with at least } 3 \mathrm{~mm} \text { roughness at about } 40 \mathrm{~mm} \text { spacing, } \\
\text { Achieved by raking, exposing of aggregate }\end{array}$ \\
\hline Indented & 0.50 & 0.9 & A surface with indentations \\
\hline
\end{tabular}


The design formula for the shear strength of Eurocode was established to calculate the shear strength developed at the interface of members having identical strength but placed at different time. It is thus necessary to verify the applicability of this design formula when those members have different strengths.

In this regard, Kang et al. [9] conducted the FE analysis for the evaluation of the shear strength in concrete layers with different strengths. The authors concluded that the analytical result is larger by $1.3-1.4$ times than the value calculated by the design formula as shown in Figure 2. And the authors also concluded that the design formula provides conservative shear strength with a safety factor of about 1.6 if calculation is done by substituting the properties of the material with lower strength in the design formula in the case of concrete layers with different strengths.

\section{Push-Out Test of Interface between Layers with Different Strengths}

\subsection{Test Variables}

Push-off test was performed to evaluate the shear strength developed at the interface between concrete layers with different strengths. The test specimens were fabricated according to the execution or not of surface treatment, the diameter of the reinforcement, and the number of shear connectors.

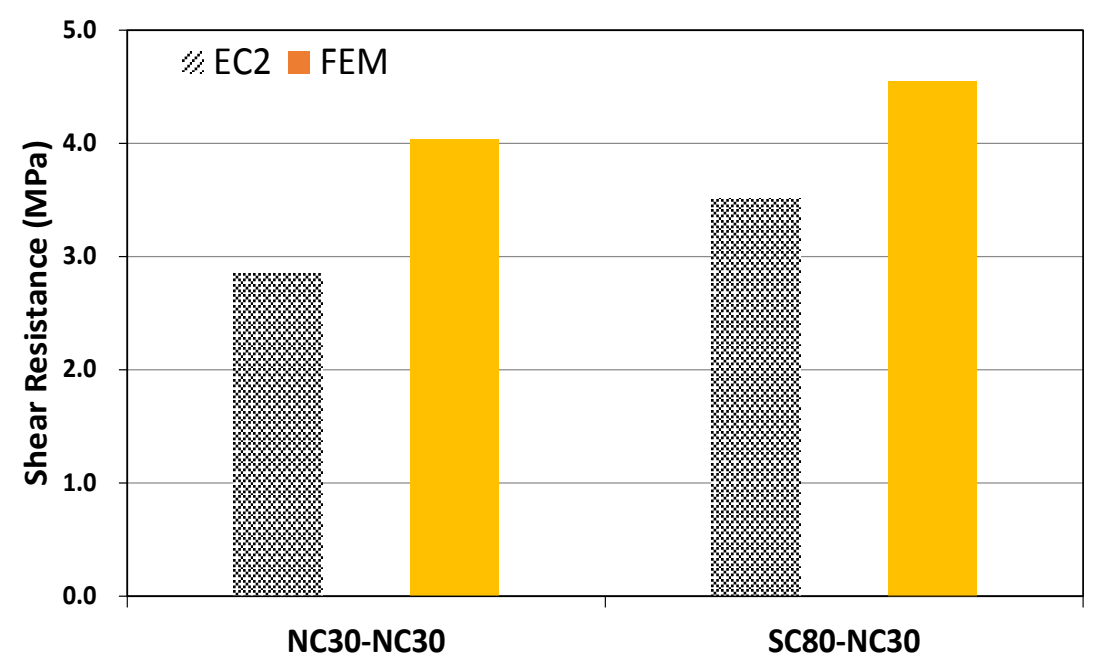

(a)

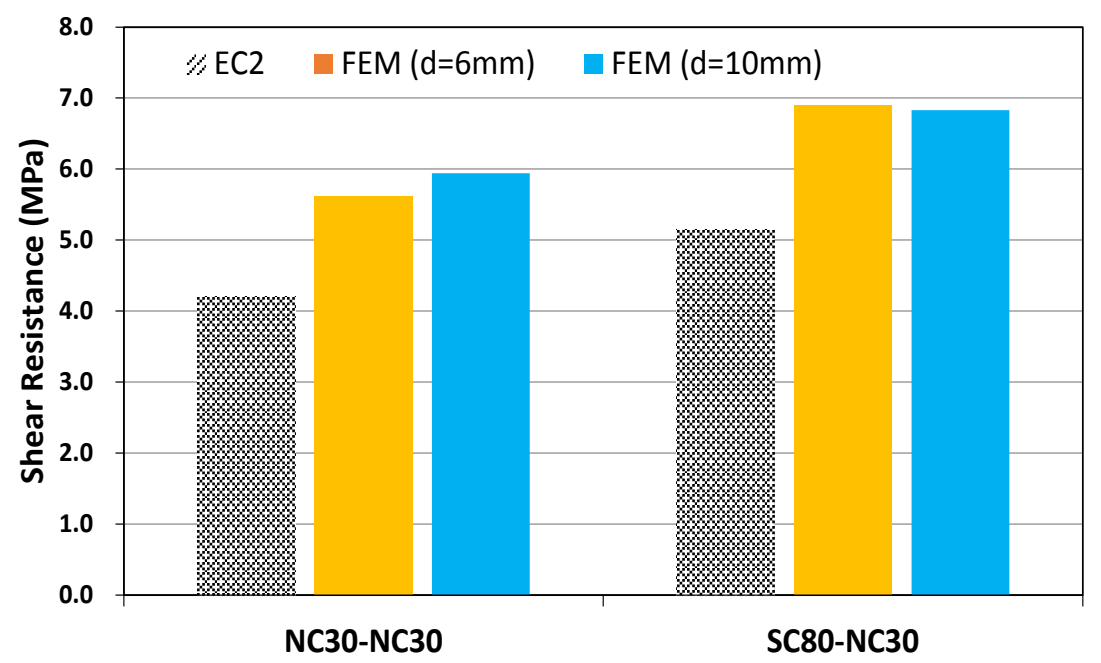

(b)

Figure 2. Comparison of shear strength obtained by FEA and calculated by Eurocode’s design formula [9]. (a) Smooth surface; (b) indented surface. 
Figure 3 presents the shape of the specimens. The upper and lower concrete blocks were made according to the considered configuration: Model NC30-SC80 and model NC30-NC30. After the fabrication, the real strengths measured through compressive test on samples were 31.8 MPa and 74.55 MPa, respectively.

As shown in Figure 4, various number of reinforcements from 1 to 6 were arranged. The interface between the concrete layers was non-treated or indented with 6-mm deep indents spaced at intervals of $40 \mathrm{~mm}$ as shown in Figure 5.

\subsection{Test Method}

The test was conducted under static loading using a UTM (Universal Testing Machine) with capacity of 2000 $\mathrm{kN}$. Loading was applied through displacement control as speed of $0.5 \mathrm{~mm} / \mathrm{min}$ until a displacement of $5 \mathrm{~mm}$ and speed of $1 \mathrm{~mm} / \mathrm{min}$ for displacements beyond $5 \mathrm{~mm}$.

As shown in Figure 6, the loading plate pushed the upper block so as to provoke the sliding motion at the interface. A vertical plate was disposed to prevent any risk of overturning. A support plate equipped with roller device was installed between the specimen and the vertical plate to eliminate the friction between the fixing jig and the specimen.
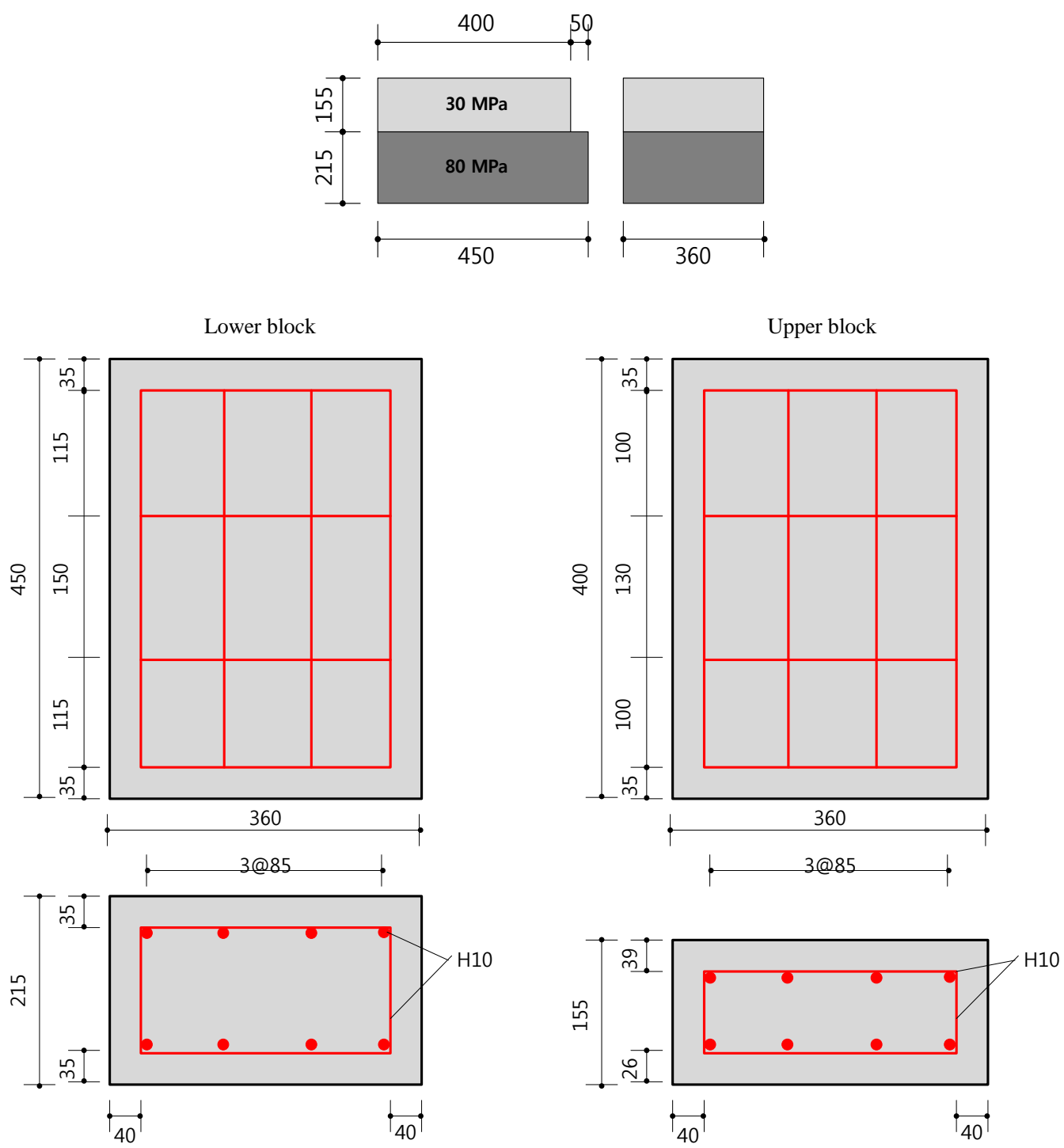

Figure 3. Shear test specimen (unit: $\mathrm{mm}$ ). 

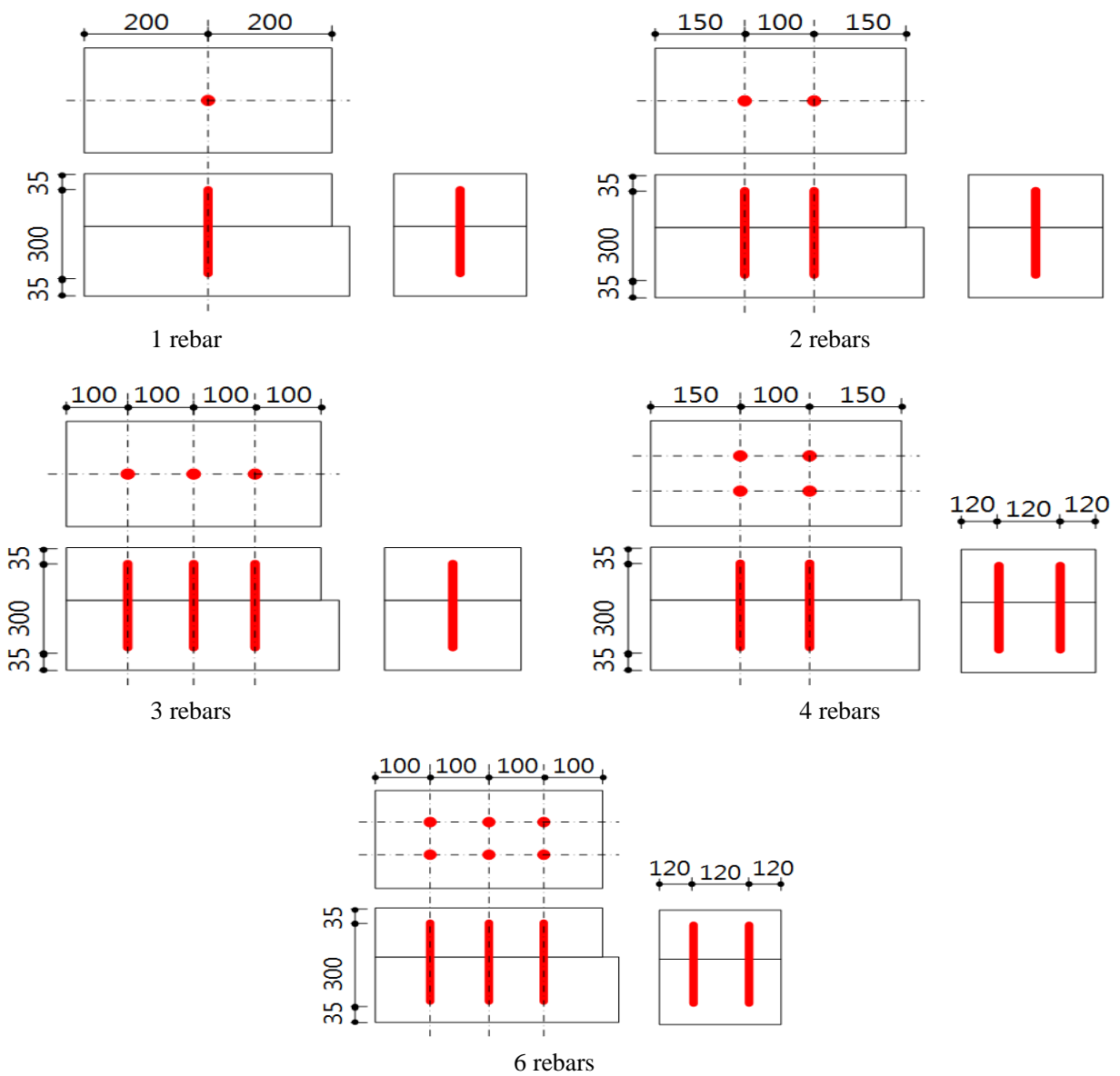

Figure 4. Arrangement of shear reinforcement (unit: mm).

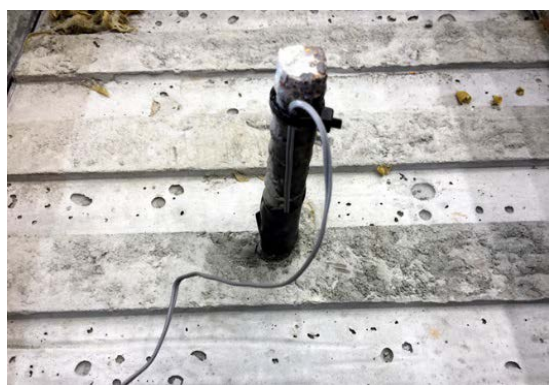

Figure 5. Indented surface.
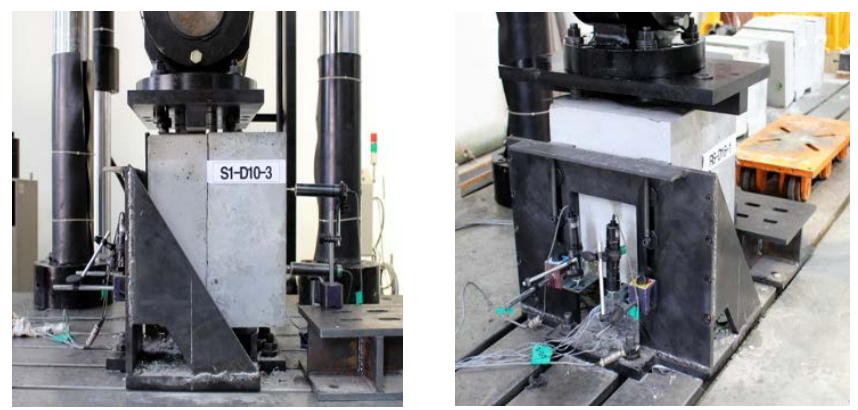

Figure 6. View of push-off test. 


\subsection{Test Results}

Table 2 arranges the test results of each specimen. A series of three specimens were fabricated for each test variable and the corresponding average is compared to the value of the shear strength calculated by the design formula.

Figure 7 plots the shear strength with respect to the reinforcement ratio of the shear reinforcement. Shear failure occurred at the interface for reinforcement ratio smaller than 4.0, but shear failure occurred together with crushing at the supporting face of the concrete block for reinforcement ratio larger than 4.0, which did not meet the expected shear strength. Considering only the cases with reinforcement ratio below 4.0, nearly all the specimens developed shear strength higher than that predicted by the design formula.

Figure 8 compares the test results and predictions of the design formula with regard to the test variables. Ex-

Table 2. Shear strength measured by shear test and comparison to design equation.

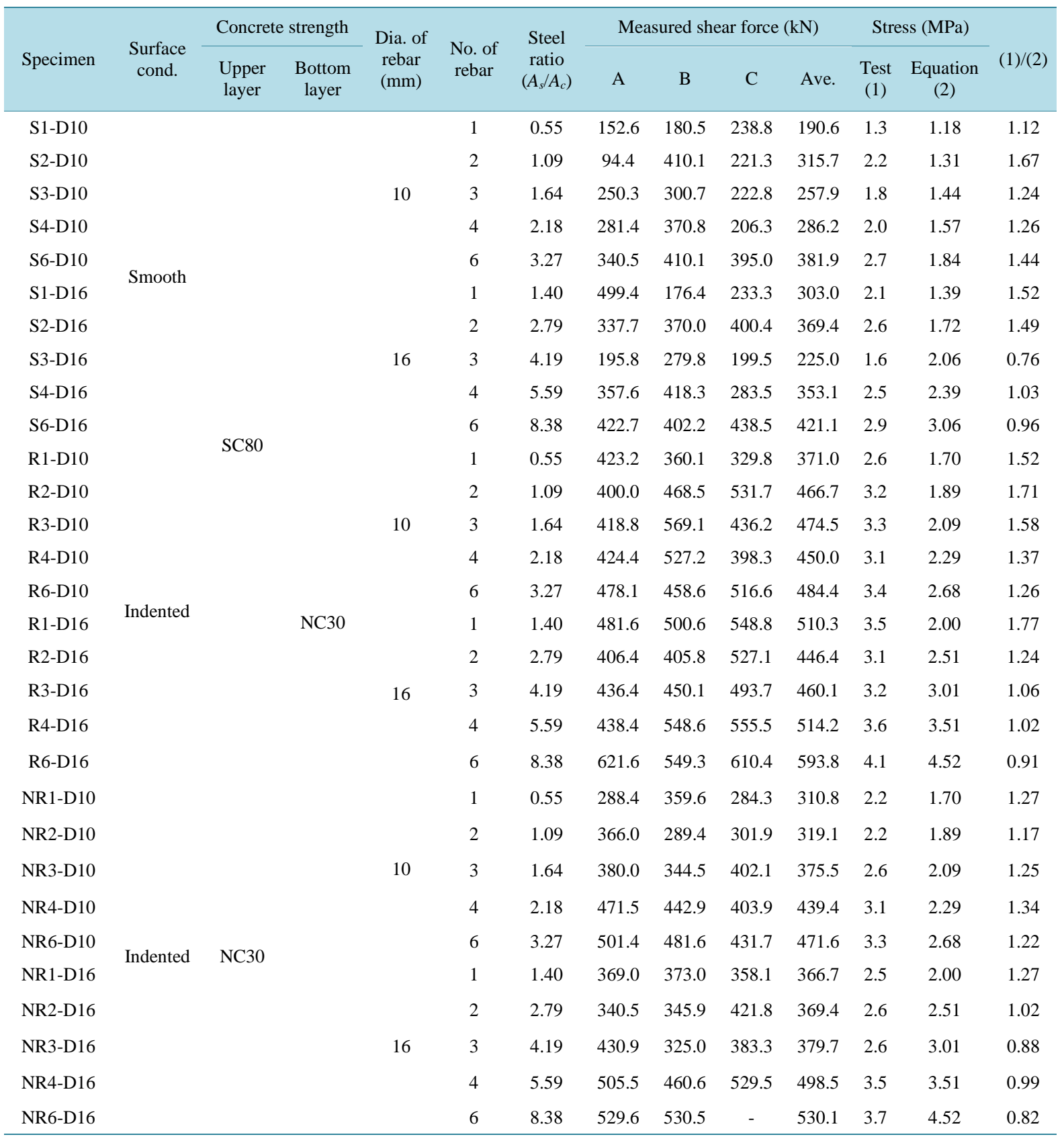




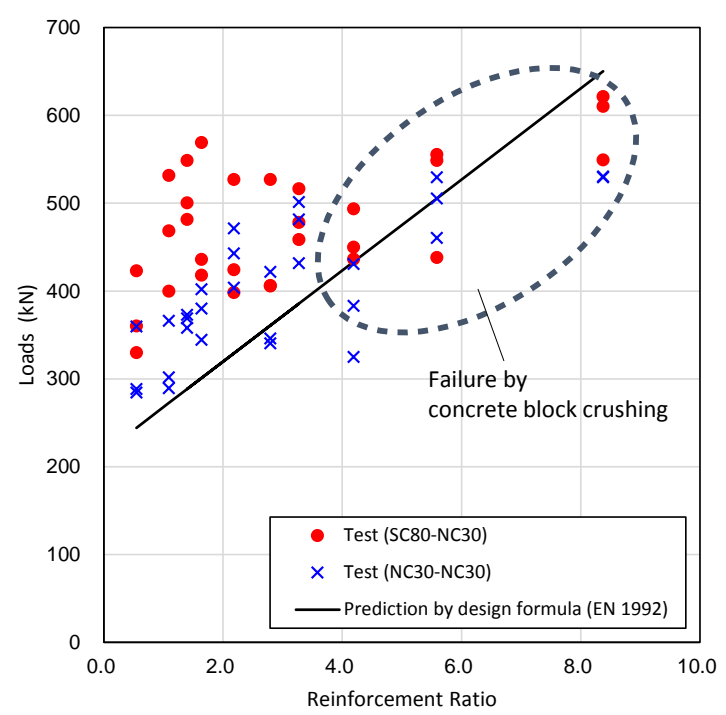

Figure 7. Shear forces to reinforcement ratio.

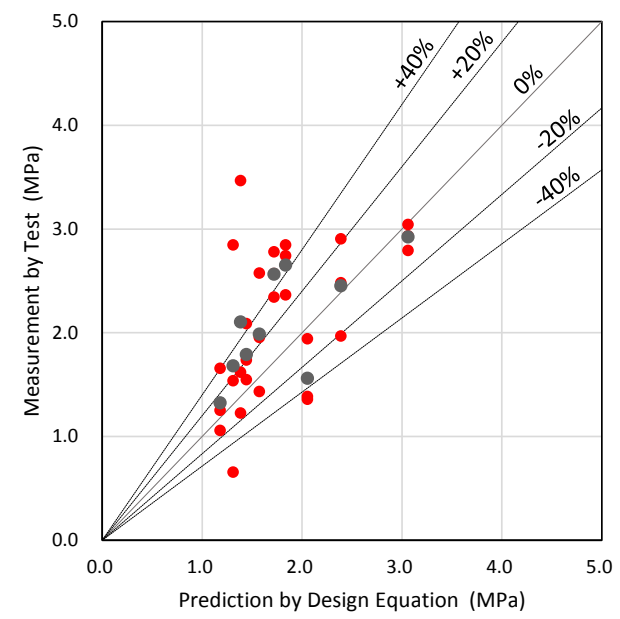

(a)

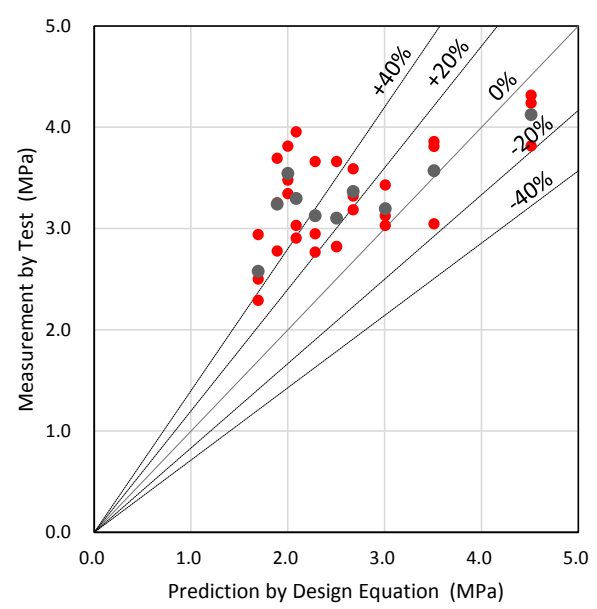

(b)

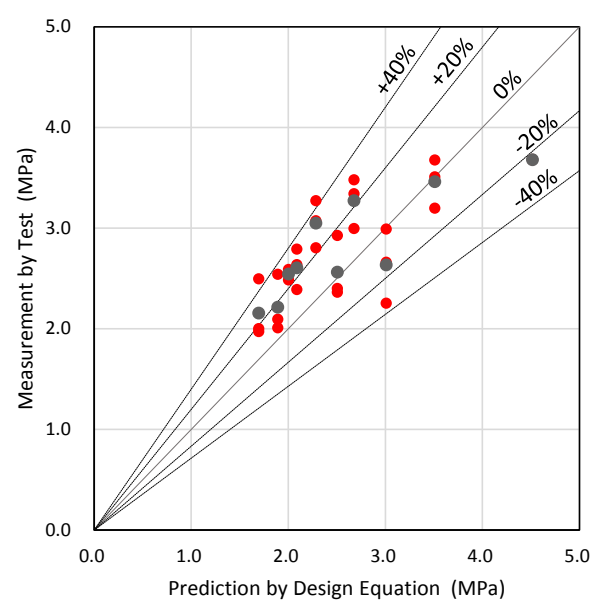

(c)

Figure 8. Comparison of test results and prediction by design formula. (a) SC80-NC30 (smooth interface); (b) SC80-NC30 (indented interface); (c) NC30-NC30 (indented interface). 
cept for the cases with reinforcement ratio larger than 4.0, the test specimens are seen to develop $20 \%$ to $40 \%$ of the shear strength predicted by the design formula. Especially, model NC30-SC80 with indented interface shows shear strength around 40\%. Besides, model NC30-NC30 with indented interface develops shear strength larger by about $20 \%$ than that predicted by the design formula.

Figure 9 compares the analytical results and predictions with regard to the interfacial surface roughness and the strength difference, respectively. The indented surface increased the shear strength by about $40 \%$ compared to the smooth surface. For the same indented surface, the difference in the compressive strength between the concrete blocks contributed to a difference of approximately $20 \%$ in the shear strength.

\section{Conclusions}

Shear test was conducted to evaluate the shear strength according to the surface roughness of the interface between concrete layers with different compressive strengths of $80 \mathrm{MPa}$ and $30 \mathrm{MPa}$. The experimental results were then compared with the predictions provided by the design formula of Eurocode. The following conclusions can be drawn.

(1) For the interface between two concrete blocks with the same compressive strength of 30 MPa (NC30NC30), the shear strength was larger by about $20 \%$ on the average compared to the prediction of the design formula. Besides, the interface between two concrete blocks with different compressive strengths of $80 \mathrm{MPa}$ and $30 \mathrm{MPa}$ (SC80-NC30) developed actual shear strength larger by more than about 40\% compared to the prediction of the design formula.

(2) Specimen SC80-NC30 experienced increase of its shear strength by about $40 \%$ owing to the presence of indents compared to the smooth interface. This increase could be attributed to the increase of the shear friction force brought by the interlocking effect of the indents. Considering that the shear resistance improved thanks to the indents, this opens room for alternatives like the reduction of the amount of shear reinforcement.

(3) In case of indented interface, the increase of the compressive strength of one concrete block to $80 \mathrm{MPa}$ improved the shear strength at the interface by about $20 \%$ compared to having two concrete blocks with the same strength of $30 \mathrm{MPa}$. Unlike the prediction of the design formula, the shear strength between two concrete layers with different strengths is expected to augment with larger difference between these compressive strengths. Accordingly, it is necessary to specify the value of the strength to be applied in the design formula, and a modified design formula shall be proposed to evaluate the shear strength between two concrete layers with different strengths by means of complementary studies.

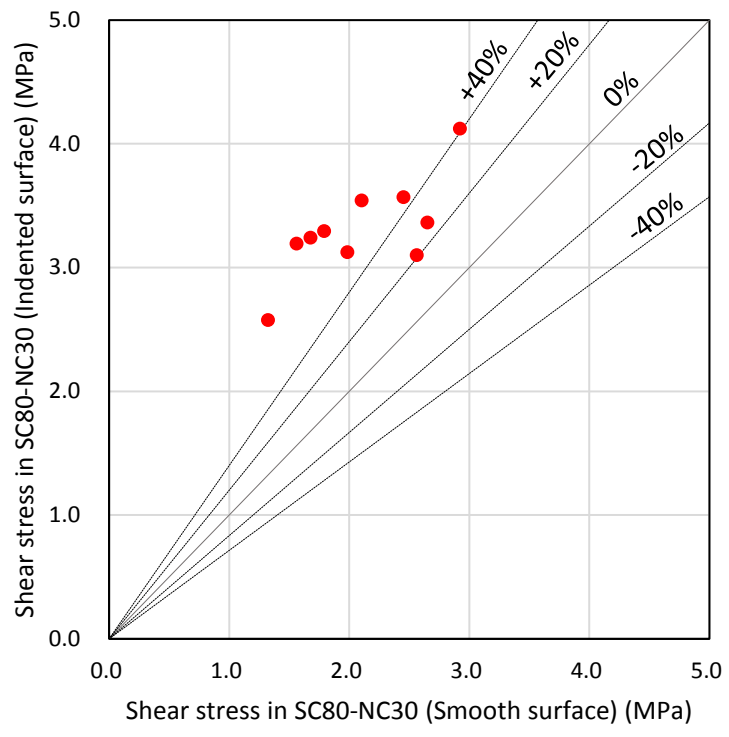

(a)

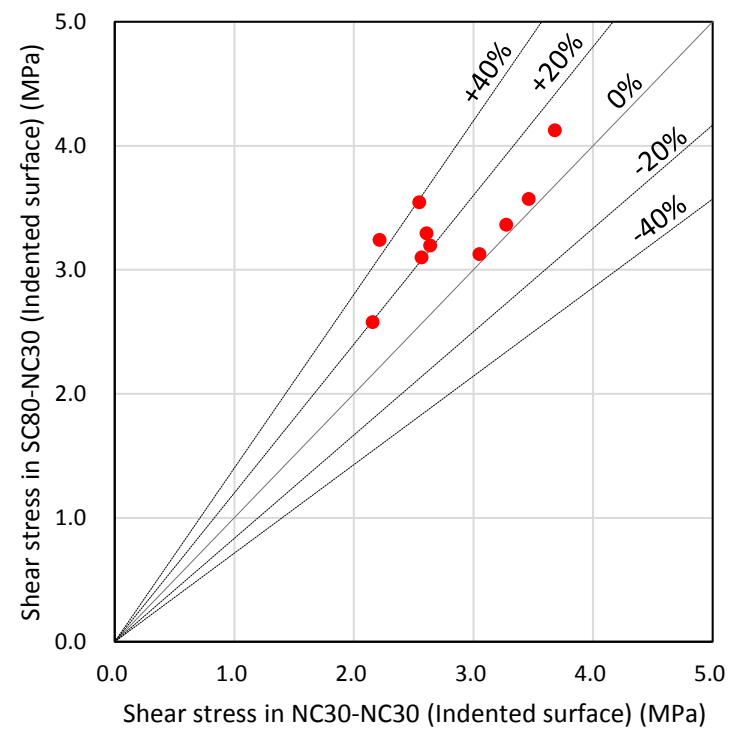

(b)

Figure 9. Comparison of shear strength with respect to design variable. (a) Interfacial condition; (b) strength of concrete layer. 


\section{Acknowledgements}

This study was supported financially through the project "Development of SUPER Concrete with compressive strength of 80 - $180 \mathrm{MPa}$ and its application (3rd year)”. The authors express their gratitude for the support.

\section{References}

[1] Hanson, N.W. (1960) Precast-Prestressed Concrete Bridges 2. Horizontal Shear Connections. Journal of the PCA Research and Development Laboratories, No. 2, 38-58.

[2] Birkeland, H.W. and Birkeland, P.W. (1966) Connections in Precast Concrete Construction. Journal of the ACI, Proceedings, 63, 345-368.

[3] Mattock, A.H. and Hawkins, N.M. (1972) Shear Transfer in Reinforced Concrete-Recent Research. Precast/Prestressed Concrete Institute, PCI Journal, 17, 55-75.

[4] Walraven, J.C. and Reinhardt, H.W. (1981) Theory and Experiments on the Mechanical Behaviour of Cracks in Plain and Reinforced Concrete Subjected to Shear Loading. Heron, 26, No. 1A.

[5] Loov, R.E. and Patnaik, A.K. (1994) Horizontal Shear Strength of Composite Concrete Beams with Rough Interface. PCI Journal, 39, 48-69. http://dx.doi.org/10.15554/pcij.01011994.48.69

[6] Júlio, E., Branco, F. and Silva, V. (2004) Concrete-to-Concrete Bond Strength. Influence of the Roughness of the Substrate Surface. Construction and Building Materials, 18, 675-681. http://dx.doi.org/10.1016/j.conbuildmat.2004.04.023

[7] Júlio, E. and Santos, P. (2010) Comparison of Methods for Texture Assessment of Concrete Surfaces. ACI Materials Journal, 107, 433-440.

[8] EN 1992-1-1 Eurocode 2: Design of Concrete Structures-Part I: General Rules and Rules for Buildings. European Committee for Standardization, 2002.

[9] Kang, J.Y., Park, J.S., Jung, W.T. and Keum, M.S. (2015) Connection between Concrete Layers with Different Strengths. Engineering, No. 7, 365-372.

\section{Submit or recommend next manuscript to SCIRP and we will provide best service for you:}

Accepting pre-submission inquiries through Email, Facebook, LinkedIn, Twitter, etc.

A wide selection of journals (inclusive of 9 subjects, more than 200 journals)

Providing 24-hour high-quality service

User-friendly online submission system

Fair and swift peer-review system

Efficient typesetting and proofreading procedure

Display of the result of downloads and visits, as well as the number of cited articles

Maximum dissemination of your research work

Submit your manuscript at: http://papersubmission.scirp.org/ 